\title{
Original Research \\ Motivation of health surveillance assistants in Malawi: A qualitative study
}

\section{Kingsley R. Chikaphupha ${ }^{1}$, Maryse C. Kok ${ }^{2}$, Lot Nyirenda ${ }^{3}$, Ireen Namakhoma ${ }^{1}$, Sally Theobald ${ }^{4}$}

1. Research for Equity and Community Health (REACH) Trust, Lilongwe, Malawi

2. Royal Tropical Institute, Amsterdam, the Netherlands

3. University of Livingstonia, Livingstonia, Malawi

4. Department of International Public Health, Liverpool School of Tropical Medicine, Liverpool, United Kingdom

Correspondence to: Kingsley R. Chikaphupha (kchikaphupha@gmail.com)

\section{Background}

Abstract

Motivation of health workers is a critical component of performance and is shaped by multiple factors. This study explored factors that influence motivation of health surveillance assistants (HSAs) in Malawi, with the aim of identifying interventions that can be applied to enhance motivation and performance of HSAs.

Methods

A qualitative study capturing the perspectives of purposively selected participants was conducted in two districts: Salima and Mchinji. Participants included HSAs, health managers, and various community members. Data were collected through focus group discussions $(\mathrm{n}=16)$ and in-depth interviews $(\mathrm{n}=44)$. The study sample was comprised of 112 women and 65 men. Qualitative data analysis was informed by existing frameworks on factors influencing health worker motivation.

Results

Our analysis identified five key themes shaping HSA motivation: salary, accommodation, human resource management, supplies and logistics, and community links. Each of these played out at different levels—individual, family, community, and organisational—with either positive or negative effects. Demotivating factors related primarily to the organisational level, while motivating factors were more often related to individual, family, and community levels. A lack of financial incentives and shortages of basic supplies and materials were key factors demotivating HSAs. Supervision was generally perceived as unsupportive, uncoordinated, and top-down. Most HSAs complained of heavy workload. Many HSAs felt further recognition and support from the Ministry of Health, and the development of a clear career pathway would improve their motivation.

\section{Conclusions}

Factors shaping motivation of HSAs are complex and multilayered; experiences at one level will impact other levels. Interventions are required to enhance HSA motivation, including strengthening the supervision system, developing career progression pathways, and ensuring clear and transparent incentives. HSAs have unique experiences, and there is need to hear and address these to better enable HSAs to cope with the challenging conditions they work in.

\section{Introduction}

The human resources for health shortage remains a key challenge to the aspiration of achieving quality universal health coverage in Malawi. In response to this, there have been increasing investments in community health worker (CHW) programmes, with the aim of bringing health services closer to communities and making services more accessible in resource-constrained settings. ${ }^{1,2} \mathrm{~A}$ CHW is a health worker who carries out promotional, preventive, or curative health services, and who is the first point of contact at the community level. A CHW can be based in the community or in a basic primary health care facility. In addition to specific aspects of their job descriptions, CHW selection criteria, remuneration and incentives, training, supervision, and support structures vary by country and depend in part on the extent to which CHWs are integrated into a health system, ${ }^{3,4}$ as well as on the degree to which task shifting has been implemented.

There has been growing global interest in assessing how motivation shapes performance of CHWs. ${ }^{6-8}$ Motivation can be defined as "an individual's degree of willingness to exert and maintain effort towards organisational goals." Motivation is linked to notions of self-fulfilment, achievement, and recognition. ${ }^{9}$ Motivation develops in each individual as a result of the interaction between individual, organisational, and cultural determinants. Effective human resource management (including supervision, training, performance appraisal, and career development) can increase motivation. ${ }^{10}$

http://dx.doi.org/10.4314/mmj.v28i2.2
In Malawi, CHWs are known as health surveillance assistants (HSAs); their history can be traced back to the 1950s when they were initially known as "public vaccinators" and later "smallpox vaccinators". ${ }^{11}$ The Ministry of Health (MOH) defines an HSA as a primary healthcare worker serving as a link between a health facility and the community. ${ }^{12,13}$ There are currently around 9173 HSAs in Malawi (MOH Chief Environmental Health Officer. Personal communication. 2015). The HSAs are a centrally recruited government-paid cadre, and their engagement takes place within the context of human resources shortages. ${ }^{14,15}$ Currently, HSAs' tasks include community health, family health, environmental health, prevention and control of communicable diseases, and community case management, including HIV, malaria, diarrhoeal diseases, pneumonia, and undernutrition. ${ }^{12,13,16}$ An HSA is expected to serve a population of approximately 1000 people. However, the actual size of their catchment populations is often more than this.

Earlier studies within Malawi identified several constraints to HSA work. ${ }^{8,11,12,17-20}$ Besides a heavy workload resulting from multiple tasks and large catchment areas, HSAs also face challenges related to poor remuneration, inadequate supplies and materials, and lack of a clear career path.,17 Hermann et al. found that in Malawi, Uganda, and Ethiopia, CHWs cannot be retained in the long term if they do not receive adequate remuneration, and that insufficient attention to supervision and continuous training leads to decreasing quality of programmes over time. ${ }^{21}$ Despite the available evidence, the voices and experiences of HSAs, in terms 
Table 1: Overview of focus group discussions and in-depth interviews conducted

\begin{tabular}{|c|c|c|c|c|}
\hline Qualitative Method & Mchinji & Salima & Participant categories & $\begin{array}{c}\text { No. of } \\
\text { participants }\end{array}$ \\
\hline & 1 & 2 & Health surveillance assistants & 19 \\
\hline $\begin{array}{c}\text { Focus group } \\
\text { discussions (FGDs) }\end{array}$ & 8 & 5 & $\begin{array}{l}\text { Community members (women with under-five } \\
\text { children; volunteers) }\end{array}$ & 114 \\
\hline Total No. of FGDs & 9 & 7 & Total No. of FGD participants & 133 \\
\hline \multirow{4}{*}{$\begin{array}{l}\text { Semi-structured } \\
\text { in-depth interviews } \\
\text { (IDIs) }\end{array}$} & 4 & 1 & Health surveillance assistants & 5 \\
\hline & 1 & 2 & Senior health surveillance assistants & 3 \\
\hline & 6 & 6 & Community members & 12 \\
\hline & 10 & 14 & $\begin{array}{l}\text { Health systems staff and representatives from } \\
\text { non-governmental organisations }\end{array}$ & 24 \\
\hline Total No. of IDIs & 21 & 23 & & 44 \\
\hline
\end{tabular}

Coded transcripts were then entered into an electronic qualitative data management and analysis software programme (NVivo 10; QSR International, Doncaster, Australia).

During the analytical process we adapted and refined two analytical frameworks on motivation by Alam et al. ${ }^{6}$ and Franco et al. ${ }^{9}$ to make them more suitable to the Malawian context. Study findings were validated with the two district health offices in a workshop. of barriers to and facilitators of motivation, have not yet been analysed in relation to current conceptual frameworks regarding motivation and performance. ${ }^{6,9}$ This paper addresses this gap through analysing perspectives of HSAs and other key stakeholders according to existing frameworks on motivation, with the aim of developing recommendations for strategies to increase the motivation and, ultimately, the performance of HSAs.

\section{Methods}

This study was part of broader explorative qualitative research that assessed the factors influencing the performance of HSAs in the districts of Mchinji and Salima. We used qualitative methods, including focus group discussions (FGDs) and semi-structured in-depth interviews (IDIs), with purposively selected participants, in order to obtain in-depth contextual insights into the factors influencing motivation among HSAs. Mchinji and Salima were selected in consultation with the study Country Advisory Group and represent both rural (including "hard-to-reach" populations-defined as populations living further than eight kilometres from a health facility) and semi-urban areas. Selection of the districts was also based on both districts being in the central region and having non-governmental organisations (NGOs) working with HSAs in maternal and child health.

Study respondents were purposefully selected to represent HSAs, the community (women with under-five children, volunteers, traditional birth attendants [TBAs], and traditional leaders), and other health staff (district managers, lead health centre personnel, and representatives of NGOs). HSAs and their seniors (senior HSAs, SHSAs) were interviewed, and we ensured diversity with respect to age, sex, job experience, and area of service (hard-to-reach and not hard-to-reach).

A total of 60 FGDs and IDIs were conducted (Table 1), and these included 65 males and 112 females. The FGDs and IDIs included probing questions on a variety of factors influencing motivation and performance of HSAs. Daily debriefing sessions with all data collectors were held to discuss key findings, refine lines of inquiry, and summarise extensive field notes and observations. All interviews and FGDs were digitally recorded, transcribed, and translated into English. Data were collected from July to September 2013 by a team of six research assistants with experience of undertaking qualitative research on health, with supervision from KRC and LN.

Transcripts were read by four researchers who worked in pairs to identify potential themes and develop a coding framework.
Ethical approval for the study was obtained from the Malawi National Health Sciences Research Committee (NHSRC) and the Royal Tropical Institute (KIT), the Netherlands. Depending on their literacy levels, study participants provided either oral or written informed consent prior to data collection.

\section{Results}

Table 2 presents an overview of the five themes that emerged as key factors shaping HSA motivation. These themes are connected to the four levels in which motivational factors could be categorised: individual, family, community, and organisational. ${ }^{6}$ Cells are shaded to illustrate which theme links to which level(s); whether a sub-theme had a positive or negative effect on HSA motivation is indicated by a"+" or "-_".

\section{Table 2: Factors that motivate or demotivate HSAs}

\begin{tabular}{|c|c|c|c|c|}
\hline Theme & $\begin{array}{c}\text { Individual } \\
\text { level }\end{array}$ & $\begin{array}{c}\text { Family } \\
\text { level }\end{array}$ & $\begin{array}{c}\text { Community } \\
\text { level }\end{array}$ & $\begin{array}{c}\text { Organisational } \\
\text { level }\end{array}$ \\
\hline \multicolumn{5}{|l|}{ Financial incentives: } \\
\hline - Salary & $+1-$ & $+1-$ & & \\
\hline - Allowances & - & & & - \\
\hline Accommodation & - & - & & - \\
\hline \multicolumn{5}{|l|}{ Human resource management: } \\
\hline - Training & + & & & - \\
\hline - Supervision & & & & - \\
\hline - Workload & - & & & - \\
\hline - Career perspective & $+1-$ & & & - \\
\hline \multirow{2}{*}{\multicolumn{5}{|c|}{$\begin{array}{l}\text { - Recognition of the health } \\
\text { system }\end{array}$}} \\
\hline & & & & \\
\hline \multicolumn{5}{|l|}{ Supplies and logistics: } \\
\hline - Transport & & & - & \\
\hline - Stationery and supplies & & & & $+1-$ \\
\hline - Uniforms & & & - & - \\
\hline \multicolumn{5}{|l|}{ Community links: } \\
\hline - Community expectations & & & - & \\
\hline - Community recognition & + & & + & \\
\hline
\end{tabular}

\section{Theme 1: Financial incentives \\ Salary}

Most HSAs were dissatisfied with their remuneration, as salaries were seen as insufficient to cover the rising costs of living. Some HSAs, however, expressed gratitude for recent salary increases. Delayed payment of salaries and lack of hardship allowances, particularly for those in hard-to-reach areas, intensified levels of dissatisfaction. Decisions on salary are made at the organisational level, but the impact MMJ VOL 28 (2): June 2016 
on HSAs was expressed at the individual and family levels, as HSAs reported that salaries influence their ability to care for their families.

"Our children are like they belong to the poor person who is not a government worker, and their education is similar with those children from the village. They raise the salaries with the mouth but tax is high." (IDI, female HSA, Mchinji)

\section{Allowances}

Allowances were identified as a key factor motivating HSAs. However, the process of including allowances for attending in-service training and meetings also brought negative consequences. Each time HSAs attended a training initiative or meeting, especially those organised by NGOs, they received allowances. Participants reported that allowances varied, with some organisations paying MK1000 (about US $\$ 2$ at the time) and others MK8000 (US\$16) per day. Some HSAs, health staff, and community members reported that the "allowance culture" was contributing to laziness and conflicts among health workers. HSAs were more inclined to prioritise health programmes that provided better allowances. This culture undermined HSA motivation at the level of the organisation:

"These days different organisations are coming with trainings where they come with money. However, if one day an organisation will come to work with us for free it will be hard... because we are used to that whenever we are gathered like this we expect to sign for some money." (FGD, female HSA, Salima)

"We cannot do our work effectively if we know there is no payment or money afterwards. Instead we will be more willing to go for the organisation that will at least give us something. Otherwise you are just lucky that you have managed having the whole team of us here without giving us anything." (IDI, male SHSA, Mchinji)

\section{Theme 2: Accommodation}

HSAs perceived that their accommodation needs were not prioritised. Other health staff reported similar concerns. This situation was aggravated by the lack of an accommodation policy for HSAs. According to the MOH, HSAs are expected to reside in their catchment areas. While the $\mathrm{MOH}$ had constructed houses for clinicians, nurses, and medical assistants in rural and hard-to-reach areas, the same was not true for HSAs. Many HSAs were reluctant to be based in rural areas without proper accommodation, opting instead to reside within the closest towns to accommodate personal and family needs. The lack of electricity, running water, and poor housing facilities were the key factors that drove HSAs out of the communities they are supposed to reside in. In certain instances, communities built houses for their HSA(s), particularly in areas that had village clinics, which were highly valued by the community.

"Accommodation is another serious challenge... HS As now are demanding that they be accommodated in good houses and also in locations where they will access energy, whether solar or electricity. Of course sometimes it is not necessarily electricity, but maybe they may find themselves in a village where they are not comfortable to find themselves a house that may not meet their minimum standards." (IDI, male district manager, Mchinji)

\section{Theme 3: Human resource management Training}

Training emerged as another key factor in motivating HSAs.
HSAs attend a diverse range of training programmes and workshops, for example, when new guidelines are introduced or mass campaigns, such as the child health days, are held. Training as an incentive was linked to the individual level: it was a vehicle for career progression, distribution of materials, mentoring, capacity building, and income from allowances. However, training-related allowances also led to demotivation at the organisational level, because some HSAs left out of training workshops insisted that only those who went for training should be the ones to provide the services. Most district managers and HSAs said that a lack of harmonised allowances from organisations and government is a recipe for HSAs to "jump ship", since it was only those organisations that provided more allowances that HSAs would prefer to work with. Participants referred to "jumping ship" when they moved from one organisation to another, mainly in order to access higher allowances:

"... HSAs tend not to work because they did not go to the trainings and did not get the allowances their friends got at the trainings. So, one may not be willing to work because they did not get that money." (FGD, male HSA, Salima)

\section{Supervision}

There were clear supervision structures in place. However, HSAs and other health staff (supervisors, district managers) reported that HSAs did not usually get feedback from their supervisors, because feedback was supposed to be provided through meetings, which were often not taking place because of resource limitations. Furthermore, from the HSA perspective, feedback was seen as punitive rather than facilitative and was usually only given when it was seen that something had gone wrong. This demotivated HSAs, particularly at the organisational level:

'We do not receive any feedback, but if something didn't go well we get the feedback. But most of the times they are just silent. And we assume all is well... if you have done well they should tell you that you have done well..." (FGD, male HSA, Mchinji)

\section{Workload}

Most HSAs complained that they were overwhelmed with their work, which included supervision of volunteers and carrying out duties that are incrementally added. The illustrative quotation below highlights these HSA concerns:

'We have a number of duties because certain responsibilities which were meant for other health departments were assigned to us, because they are supposed to be performed in the communities where we stay... but salaries are the same. They don't say we have added duties on them and let us add a little money." (IDI, male SHSA, Mchinji)

Workload was associated with demotivation at the individual level (related to the dissatisfaction with the amount of salary) and the organisational level (related to the ever-rising expectations of the health system about what an HSA should be able to do).

\section{Career pathway}

There are some systems in place for career development within the MOH. However, not all HSAs were aware of such opportunities. Some HSAs reported that they saw their colleagues going for upgrading and becoming environmental health officers or moving onto more senior positions. Others thought a career path existed because they had seen other cadres, like clinicians, having a clear career path in place, and they believed that by being dedicated and working over a 
long period would mean being considered by the $\mathrm{MOH}$ for upgrading.

"I do wish to continue with my education. If I can be given a chance to do so, I would love to go and upgrade my studies at College of Health Sciences, so that maybe I can work as an assistant environmental health officer one day." (IDI, male SHSA, Salima)

There was lack of salary differentiation based on length of service and academic qualifications. Most HSAs reported that this was a major demotivating factor, as explained in this illustrative quotation:

"No, even if I am a bard worker there is no chance of being promoted... And even when you're a senior $H S A$ you receive a salary which is the same as with any other HSA. For example, our senior HSA started working as an HSA in 1993, while I started working as HSA in 2007, but we receive the same salary." (IDI, male HSA, Salima)

\section{Recognition from the health system}

All HSAs strongly felt that they were not valued enough by those at a "higher level", as compared to their fellow community extension workers in agriculture and education. HSAs regarded themselves as the "eyes" of the $\mathrm{MOH}$, acting as a bridge between the health system and the communities. The following illustrative quotation summarises many of the HSAs' sentiments:

"We are the eyes of the $\mathrm{MoH}$ in this country, and we also are a shield when it comes to protecting the community's health.

These people always come to us before they go anywhere and yet the authorities seem not to care about us at all." (FGD, male HSA, Mchinji)

\section{Theme 4: Supplies and logistics Transport}

Unavailability of transport was a major barrier to referral, leading to both community dissatisfaction and demotivation of HSAs. Women and men within communities complained about transport charges following referral, which in many cases led to households having to sell food to finance transport costs, which affected their food security. HSAs felt disempowered and unable to address this problem, leaving them feeling demotivated. Transport challenges also affected the ability of HSAs to make follow-up visits to their clients.

"In terms of follow-up, there is also a transportation problem.

The catchment of this health centre is very big... Had it been the District Health Office had provided us with motor bikes, we would not be facing the problems in the follow-up... in hard-toreach areas." (FGD, male HSA, Salima)

\section{Stationery and other supplies}

The HSAs reported that their work was hampered by shortages of stationery and other supplies. However, stationery was readily available when the HSAs were implementing projects for an NGO. Availability of stationary motivated the HSAs; it was seen as an important requisite for them to conduct their work:

"The other NGOs on programmes like community case management_this programme is about village clinics for children under five-they also belp HSAs with capacity building and support with supplies like drugs and other necessities in this programme." (IDI, male HSA, Mchinji)

\section{Uniforms}

Most HSAs described the shortage of uniforms as a demotivating factor, pointing out that most of the uniforms they had were either torn, old, or no longer fitting. Footwear and raincoats were no longer provided. HSAs regarded the uniform as important to their identity; uniforms allowed them to be recognised and respected at the community and organisational levels.

"The uniforms we wear are our identity." (IDI, female HSA, Mchinji)

\section{Theme 5: Community links}

\section{Community expectations}

While HSAs working in hard-to-reach areas were trained to run village clinics, inadequate training of some of the HSAs and inadequate supplies led to HSAs not being able to meet community expectations, leading to demotivation:

"When a child is sick they run to you expecting medicine, and if you don't help them it becomes a problem. In addition, when a woman wants family planning methods, and you don't have one they tend not to trust you." (FGD, female HSA, Salima)

"I would love the HSA to give us proper service when we approach bim with our sick children... They need to be trained professionally. It is not right to just practice without proper training, as local training from each other has its own limitations." (FGD, female community member, Mchinji)

\section{Community recognition}

HSAs felt motivated through helping the community and getting recognition. Community encouragement and feedback were positive motivators at community and individual levels.

"We also feel well appreciated by the people we help, and this encourages us to continue doing our work. This appreciation makes us feel proud that we are doing a good job." (FGD, male HSA, Mchinji)

\section{Discussion}

This is the first study to use qualitative research methods to capture the diverse perspectives of HSAs and other representatives from the health system on HSA motivation in Malawi and analyse them through the application of existing and established frameworks on motivation. With the exception of research conducted in Tanzania, ${ }^{7}$ this is the first time these frameworks have been applied to analyse motivation of CHWs in Africa.

Our analysis identified five key themes shaping HSA motivation: salary, accommodation, human resource management, supplies and logistics, and community links. Each of these played out at more than one of the overlapping levels identified in the motivational frameworks-individual, family, community, and organisational — with either positive or negative effects (Table 2). The factors shaping motivation of HSAs are complex and multilayered; experiences at one level will impact other levels.

Many of the components shaping HSA motivation link to extrinsic factors emanating from the organisational level. Four of the five key themes are linked to the organisational level, with many of these proving sources of dissatisfaction and acting as demotivating factors. Within the Malawian context, dissatisfaction with salary and allowances is further complicated by the $\mathrm{MOH}$ and NGOs simultaneously providing different rates of HSA allowances, leading to opportunities for HSAs to "jump ship". With HSAs feeling disgruntled about salaries and allowances, they are likely to prioritise the work of those who offer the highest financial 
benefits, leading to unintended consequences for the health system in Malawi. The allowance culture is particularly pervasive because allowances for travel and training are seen as supplementary income for health workers in Malawi. ${ }^{22}$ HSAs are also motivated by training and opportunities to develop their careers further; although, many feel that within the HSA cadre, there are no incentives to do this, as SHSAs receive the same financial package as more junior HSAs. There is need to develop new models of supportive supervision and put in place a system for rewarding HSAs. The $\mathrm{MOH}$ is currently making strides to address the situation and has recently developed a grade structure (grade L) for SHSAs, with a salary structure commensurate with education levels and experience (MOH Deputy Director and Country Advisory Group member. Personal communication. 2015). There is a clear need to review and harmonise the financial rewards for HSAs across the board and introduce a fair and transparent system. Investing in policies and practices that support and recognise HSAs at the organisational level can positively influence motivation.

The main source of motivation for many HSAs came from the community level. Community embedment can affect motivation through enhanced appreciation by the population. ${ }^{3}$ This motivating factor needs to be maintained, and therefore it is important that HSAs are supplied with the necessary supplies and equipment to avoid community mistrust. Different HSAs have different levels of embedment, which could depend on whether they originate from the communities they serve and whether they live within these communities. ${ }^{23}$ The location of an HSA's residence is influenced by accommodation options and expectations, and worryingly it appears that HSAs are often not willing to live in the poor rural and hard-to-reach communities. Investing in improving accommodations for HSAs and hardship allowances could reverse this trend and ensure that HSAs reside within the communities in which they work, including hard-to-reach areas. Another option to ensure that HSAs' reside in their communities is to adjust the recruitment and selection system by recruiting new HSAs from the communities that they are supposed to serve, combined with a bonding scheme to keep them there for a specified duration.

The family did not clearly emerge as source of motivation in either the literature or our findings. However, family members did emerge as a source of support in terms of encouraging HSAs to continue working under their prevailing circumstances, which the HSAs themselves mostly described as demotivating. The dissatisfaction with financial incentives and the tendency to "jump ship" also relate to family commitments and responsibilities. Poverty is a reality in most rural Malawian communities and HSAs have multiple obligations placed upon them by their immediate and extended families, and hence developing a fair and transparent package tied to the cost of living will be beneficial on multiple levels.

Individual HSAs differ greatly in terms of their goals, motives, and values. Health workers with a strong self-concept in work-related areas, and a strong sense of self-efficacy, are more likely to accept difficult organisational objectives and to persist at a task longer in the face of obstacles than persons with poor self-concept and low self-efficacy. ${ }^{24}$ This was evident in our study findings, where despite the prevailing constraints in the health system, some HSAs could be seen to be more motivated and regarded the role they played in community health as worthwhile. Health worker motivation exists when there is alignment between individual and organisational goals, and when workers perceive that they can carry out their tasks. ${ }^{9}$ Given the fluidity and interaction of factors shaping motivation, it is important to discuss which investments will have the most positive impact. Policy makers must consider organisation-level measures as a source of motivation of HSAs and realise, as demonstrated in Table 2, that support provided by the health system can reinforce motivation at individual, family, and community levels. Key priorities include reviewing a transparent process for pay, supportive supervision, accommodation, and training opportunities, coupled with clear pathways for career progression.

Our findings are in agreement with those of Kok and Muula. ${ }^{8}$ This reaffirms that the factors that influence HSA motivation are similar across different districts in Malawi. In addition, it seems that many of the constraints that were present in 2009 were still not addressed at the time of the FGDs and IDIs in 2013, and that further action is required to build stronger community health services.

There are several limitations to this study. The initial purpose was broad and not solely focused on motivation; thus, opportunities for follow-up probing and questions that could have further unpacked different elements of motivation may have been missed. The possibility of social desirability bias was minimised through using an experienced Malawian research team whose members were not associated with the HSA programme. The findings were generated in the Mchinji and Salima contexts but are likely to have a broader resonance across other rural Malawian districts.

\section{Conclusions}

CHWs' voices are not often heard in discussions of policy and practice within Malawi and beyond. We have used qualitative research methods to capture and holistically analyse the multiple factors that interplay to shape the motivation of this cadre who work at a critical interface between health systems and poor and marginalised communities. In a context of acute human resource shortages in Malawi, there is need for policy makers to understand and address these realities through an enabling policy environment, to enhance HSA motivation and thereby improve community-based health systems in Malawi. This study was conducted to inform the development of quality improvement interventions in both districts. These interventions are ongoing and include the introduction of peer and group supervision and performance appraisal, aiming to improve motivation among HSAs.

\section{Acknowledgements}

The study presented in this paper is part of the REACHOUT programme. This programme has received funding from the European Union Seventh Framework Programme ([FP7/2007-2013] [FP7/2007-2011]) under grant agreement $\mathrm{n}^{\circ}$ 306090. The authors would like to thank the European Union for funding REACHOUT. The authors would like to acknowledge all respondents who gave their time to be interviewed, as well as the qualitative data collection team who conducted and transcribed interviews. We would like to acknowledge the input of all participants in the research; we are grateful for their time and their willingness to discuss their experiences with us. We would also like to acknowledge the CAG members. Many thanks also to Miriam Taegtmeyer and Malabika Sarker for commenting on the paper. 


\section{References}

1. Bhutta ZA, Lassi ZS, Pariyo G, Huicho L. Global experience of community health workers for delivery of health-related Millennium Development Goals: a systematic review, country case studies and recommendations for scaling up. Geneva: World Health Organization; 2010.

2. Standing H, Chowdhury AMR. Producing effective knowledge agents in a pluralistic environment: What future for community health workers? Soc Sci Med. 2008;66(10):2096-107.

3. Kok MC, Dieleman M, Taegtmeyer M, Broerse JEW, Kane SS, Ormel $\mathrm{H}$, et al. Which intervention design factors influence performance of community health workers in low- and middle-income countries? A systematic review. Health Policy Plan. Oxford University Press; 2015 Nov;30(9):1207-27.

4. Zulu JM, Kinsman J, Michelo C, Hurtig A-K, Lehmann U, Sanders $\mathrm{D}$, et al. Hope and despair: community health assistants' experiences of working in a rural district in Zambia. Hum Resour Health. BioMed Central; 2014 Dec 25;12(1):30.

5. Chopra M, Munro S, Lavis JN, Vist G, Bennett S. Effects of policy options for human resources for health: an analysis of systematic reviews. Lancet. 2008;371(9613):668-74.

6. Alam K, Tasneem S, Oliveras E. Retention of female volunteer community health workers in Dhaka urban slums: a case-control study. Health Policy Plan. Oxford University Press; 2012 Sep;27(6):477-86.

7. Greenspan JA, McMahon SA, Chebet JJ, Mpunga M, Urassa DP, Winch PJ, et al. Sources of community health worker motivation: a qualitative study in Morogoro Region, Tanzania. Hum Resour Health. BioMed Central; 2013 Dec 10;11(1):52.

8. Kok MC, Muula AS. Motivation and job satisfaction of health surveillance assistants in Mwanza, Malawi: an explorative study. Malawi Med J. Medical Association of Malawi; 2013 Mar;25(1):5-11.

9. Franco LM, Bennett S, Kanfer R. Health sector reform and public sector health worker motivation: a conceptual framework. Soc Sci Med. 2002;54(8):1255-66.

10. Martinez J. Assessing quality, outcome and performance management. Workshop on Global Health Workforce Strategy Annecy. Geneva: World Health Organization; 2001. p. 9-12.

11. Callaghan-Koru JA, Gilroy K, Hyder AA, George A, Nsona $\mathrm{H}$, Mtimuni A, et al. Health systems supports for community case management of childhood illness: lessons from an assessment of early implementation in Malawi. BMC Health Serv Res. BioMed Central; 2013;13(1):55.

12. Kadzandira JM, Chilowa WR. The Role of Health Surveillance Assistants (HSAs) in the Delivery of Health Services and Immunisation in Malawi Study carried out by. Lilongwe: Ministry of Health and Population (Malawi); 2001.
13. Ministry of Health and Population (Malawi). Health surveillance assistant course curriculum. Lilongwe: Ministry of Health and Population (Malawi); 2009.

14. Hermann K, Zamadenga B, Ndeni A, Steven L. Improved health posts and patient support attendants: description and evaluation of the community HIV/AIDS programme of MSF in Thyolo. Thyolo: Médecins Sans Frontières; 2012.

15. Manafa O, McAuliffe E, Maseko F, Bowie C, MacLachlan M, Normand C, et al. Retention of health workers in Malawi: perspectives of health workers and district management. Hum Resour Health. BioMed Central; 2009 Dec 28;7(1):65.

16. Ministry of Health (Malawi). Health Surveillance Assistant Facilitator's Guide. Lilongwe: Ministry of Health (Malawi); 2009.

17. Gilroy KE, Callaghan-Koru JA, Cardemil C V, Nsona H, Amouzou A, Mtimuni A, et al. Quality of sick child care delivered by Health Surveillance Assistants in Malawi. Health Policy Plan. Oxford University Press; 2013 Sep;28(6):573-85.

18. Martiniuk A, Smith S, Deveridge A, Berman J, Negin J, Mwambene $\mathrm{N}$, et al. Getting treatment and care to the last mile: analyzing the health surveillance assistant cadre in Malawi. CIGI Africa Initiat Discuss Pap Ser. 10.

19. Nsona H, Mtimuni A, Daelmans B, Callaghan-Koru JA, Gilroy K, Mgalula L, et al. Scaling Up Integrated Community Case Management of Childhood Illness: Update from Malawi. Am J Trop Med Hyg. American Society of Tropical Medicine and Hygiene; 2012 Nov 7;87(5 Suppl):54-60.

20. Smith S, Deveridge A, Berman J, Negin J, Mwambene N, Chingaipe E, et al. Task-shifting and prioritization: a situational analysis examining the role and experiences of community health workers in Malawi. Hum Resour Health. BioMed Central; 2014 Dec 2;12(1):24.

21. Hermann K, Van Damme W, Pariyo GW, Schouten E, Assefa Y, Cirera A, et al. Community health workers for ART in sub-Saharan Africa: learning from experience - capitalizing on new opportunities. Hum Resour Health. BioMed Central; 2009 Dec 9;7(1):31.

22. Søreide T, Tostensen A, Skage IA. Hunting for per diem: the uses and abuses of travel compensation in three developing countries. Oslo: Norwegian agency for development cooperation (Norad); 2012.

23. Perry H, Townsend J, McQueen S, Adano U, D'Harcourt E, Newsome M, et al. Final report of evidence review team 1: which community support activities improve the performance of community health workers? A review of the evidence and of expert opinion with recommendations for policy, practice and research. Washington, D.C.: Kaiser Family Foundation; 2012.

24. Lunenburg FC. Self-efficacy in the workplace: implications for motivation and performance. Int J Manag Business Adm. 2011;14(1). 